\title{
Erratum \\ Effect of Sulfite Exposure on Zinc, Iron, and Copper Levels in Rat Liver and Kidney Tissues
}

\author{
Vural Kucukatay, ${ }^{*}, 1$ Sebahat Turgut, ${ }^{1}$ \\ Erdogan Kocamaz, ${ }^{2}$ Gulten EmMungil, ${ }^{1}$ \\ MeleK Bor-Kucukatay, ${ }^{1}$ Gunfer Turgut, ${ }^{1}$ Hakan Akca, ${ }^{4}$ \\ AND HUSEYIN BAGCl ${ }^{3}$ \\ Departments of ${ }^{1}$ Physiology, ${ }^{2}$ Histology and Embryology, \\ and ${ }^{3}$ Medical Biology, Faculty of Medicine, and ${ }^{4}$ Department \\ of Biology, Faculty of Arts \& Science, Pamukkale University, \\ Kinikli 20020, Denizli, Turkey
}

Owing to a printer's error, the incorrect figures and discussion were printed. The correct figures 1-3 and the Results section are reprinted here. 


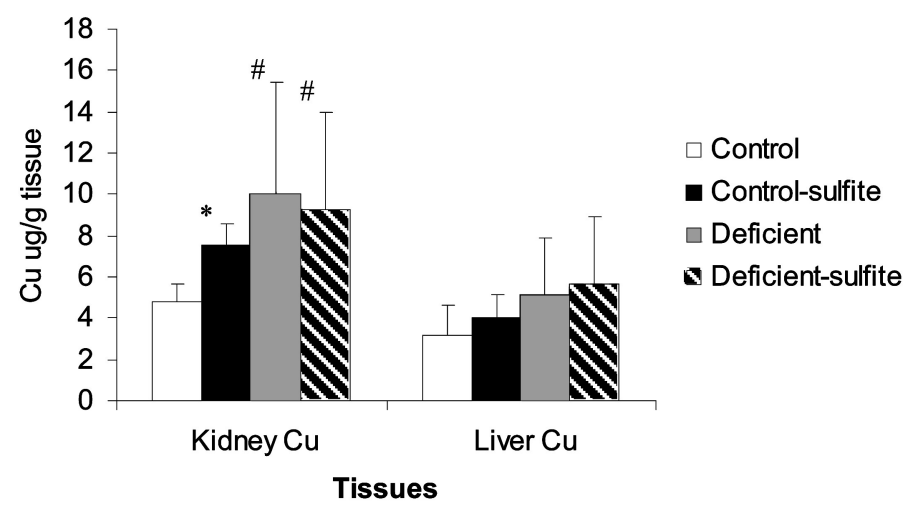

Fig. 1. Effects of sulfite treatment on the kidney and liver $\mathrm{Cu}$ levels in normal and SOX-deficient rats. The values are expressed as means $\pm S E(n=10)$. C = controls; $\mathrm{S}=$ normal SOX, sulfite treated; $\mathrm{D}=$ SOX-deficient controls; DS = SOX deficient, sulfite treated.

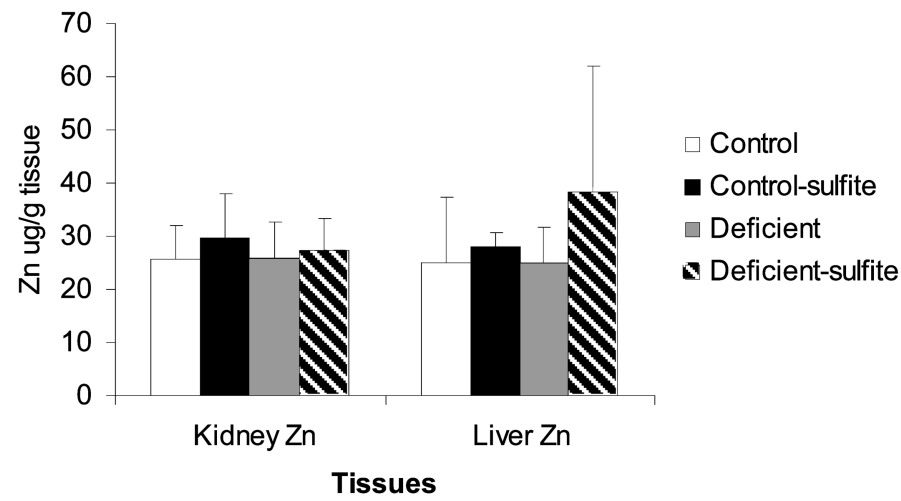

Fig. 2. Effects of sulfite treatment on the kidney and liver $\mathrm{Zn}$ levels in normal and SOX-deficient rats. The values are expressed as means $\pm S E(n=10)$. $C=$ controls; $\mathrm{S}=$ normal SOX, sulfite treated; $\mathrm{D}=\mathrm{SOX}$-deficient controls; $\mathrm{DS}=\mathrm{SOX}$ deficient, sulfite treated. ${ }^{*} p<0.001$.

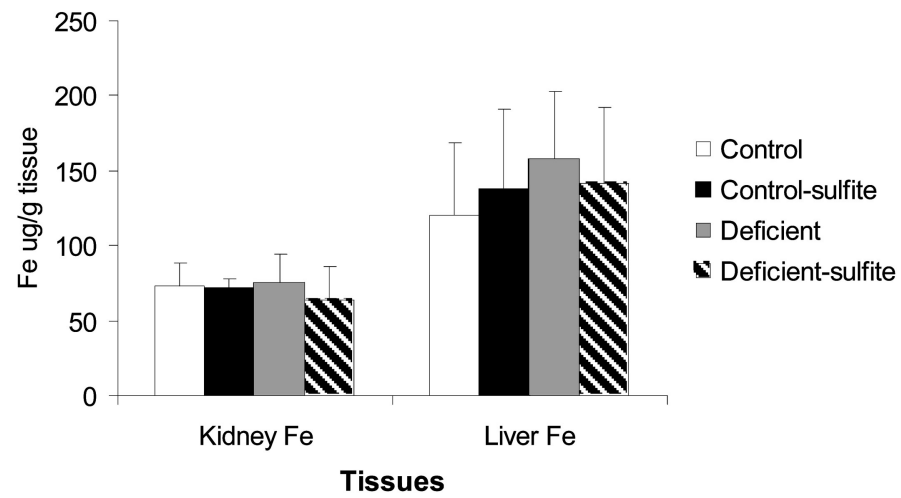

Fig. 3. Effects of sulfite treatment on the kidney and liver Fe levels in normal and SOX-deficient rats. The values are expressed as means $\pm S E(n=10)$. C $=$ controls; $\mathrm{S}=$ normal SOX, sulfite treated; $\mathrm{D}=\mathrm{SOX}$-deficient controls; $\mathrm{DS}=\mathrm{SOX}$ deficient, sulfite treated. 


\section{RESULTS}

The enzymatic activity of SOX can be used an indicator for status of SOX in animals (19). Our results clearly show that maintaining the animals on a high-W, low-Mo diet effectively induced SOX deficiency. The SOX activity was about 15 times lower in deficient rats with respect to controls and the difference was highly significant $(p<0.0001)$. The effect of sulfite treatment on the hepatic SOX activity of rats in all groups at the end of the experimental period is shown in Table 1. The SOX activities of sulfitetreated animals were not altered in either normal or deficient groups.

The kidney $\mathrm{Cu}$ content of controls was $4.84 \pm 0.82 \mu \mathrm{g} / \mathrm{g}$ tissue. Rats maintained under conditions similar to controls but receiving sulfite for 6 wk had kidney $\mathrm{Cu}$ values of $7.56 \pm 1.01 \mu \mathrm{g} / \mathrm{g}$ tissue, a highly significant increase $(p<0.001)$.

Animals made deficient without sulfite exposure also had significantly higher $\mathrm{Cu}$ values: $10.02 \pm 5.44 \mu \mathrm{g} / \mathrm{g}(p<0.003)$. Exposure to sulfite caused only insignificant increases (Fig. 1).

In both normal and SOX deficient animals, exposure to sulfite did not induce any significant alterations of Zn (Fig. 2) and Fe content in kidney and liver tissues (Fig. 3). 